Original Article

\title{
THE RELATION BETWEEN INTERNET, DEPRESSION, SELF-ESTEEM AND SOCIAL ATTACHMENT ON COGNITIVE FUNCTION OF HEALTH CARE INDIVIDUALS
}

\author{
VIKHRAM RAMASUBRAMANIAN ${ }^{1}$, RAJESH VENKATARAMAN ${ }^{2}$, P. RAJA SOUNDARA PANDIAN ${ }^{1}$, GOPAL TELI², \\ NIRAJ SHRESTHA ${ }^{2}$
}

1Ahana Hospital, Madurai, ${ }^{2}$ Department of Pharmacy Practice, Sri Adichunchanagiri College of Pharmacy, B. G. Nagara 571448, Karnataka, India

Email: rajeshvenky_research@hotmail.com

Received: 13 Apr 2017 Revised and Accepted: 27 May 2017

\begin{abstract}
Objective: To assess the internet use in health care individuals and its impact on depression, self-esteem and social attachment on cognitive function of health care individuals.

Methods: This was a cross-sectional survey which included one hundred and ten healthcare individuals (Physician, Pharmacist, Psychologist, Social worker and Nurses) in this study conducted in Radianz healthcare and research private limited. Young's internet addiction test and depression score, self-esteem (Rosenberg's) score and MoCA were used to measure internet addiction and psychological variables. EPI 2012 was used for statistical analysis.

Results: Out of 110 individuals, the majority of individuals, depressed individual were more addicted to the internet and found to be significant by using depression score. Relationship between baseline values and follow up values in internet addiction was significant $(\mathrm{P}=0.07636)$. After follow up the internet addiction found to be reduced as it was greatly affected in initial survey.

Conclusion: This study concluded that there is relationship between the internet addiction and depression, cognitive function and self-steam. The depressed individuals were more addicted to the internet followed by abnormal cognitive function and low self-esteem individuals. Internet addiction may be a relevant clinical construct and early diagnostic tools that needs extensive research even in developing nations to explore the relationship. Depression is greatly associated with the internet addiction so if can we reduce the depression then can be reduced internet addiction.
\end{abstract}

Keywords: Cross-sectional survey, Internet addiction, Depression, MoCA and self-esteem

(C) 2017 The Authors. Published by Innovare Academic Sciences Pvt Ltd. This is an open access article under the CC BY license (http://creativecommons.org/licenses/by/4.0/) DOI: http://dx.doi.org/10.22159/ijpps.2017v9i7.19132

\section{INTRODUCTION}

Healthy use of the internet is defined as the use of the internet to achieve a desired goal within an appropriate period of time without intellectual or behavioral discomfort [1]. People throughout the world have found the internet to be a fast and easy was to gather information and to interact. However, some people lose control over their internet-related behavior, leading to difficulties in their daily lives and family [2]. Such uncontrolled behavior has been described as "internet addiction" or "problematic internet use", and this problem has been suggested to constitute a behavioral addiction [3,4]. Like other non-chemical addictions such as those involving gambling, sex, and shopping, the primary features of internet addiction include preoccupation, emotional liability, tolerance, withdrawal, interpersonal conflict, and engagement in repetitive behaviors. Among co-morbid disorders, depressive disorders have been most prominently related to internet addiction as well as anxiety disorders, and substance-related addictions [5]. The prevalence of internet addiction is high among young people due to their unsettled personalities and has been reported to vary from $1.5 \%$ to $24.2 \%$ [1]. The rate of internet usage was $22.4 \%$ in South Korea in 1999 , but by June 2002 this had more than doubled to $58 \%$, or 25.65 million people. Similarly, the proportion of U. S. homes with internet access increased significantly from $26.2 \%$ in December 1998 to more than half of the nation in September 2001 [6]. Depression manifests as deep sorrow or grief, insomnia, loss of appetite, unpleasant mood, hopelessness, irritability, self-dislike, and suicidal tendencies [1]. Low self-esteem, low motivation, fear of rejection and the need for confirmation from others, all of which are commonly observed in depressive people, may result in frequent use of the internet and theinteractive functions of the internet may lead to internet addiction in individuals with these characteristics [7].
Self-esteem is described as a person's attitude to himself; it can be positive or negative. Self-esteem is accepted that while a person perceives himself positively, self-esteem is high, but if the person perceives himself negatively, self-esteem is low. It has been suggested that low self-esteem is a principal component of depression [2]. As a coping strategy, people who have negative beliefs about themselves like having low self-esteem may tend to be addicted to be relieved from the their negative beliefs, self-esteem has a relationship with perfectionism and maladaptive perfectionism was found to be a negative predictor of self-esteem [2].

Internet addiction is more common in males than in females [8] Gender differences in the preferred online activity have also been reported. For example, in adolescents with internet addiction, online gaming is the most common internet activity in males but not in females [9]. Researchers have suggested that Internet addiction might be related to cognitive function, on the one hand, people with deficits in certain aspects of cognitive functioning are more likely to be addicted to the Internet than those who have intact cognitive functioning. On the other hand, there is the possibility that internet addiction causes deficits in some cognitive functions [11].

The treatment approach of internet addiction is advisable and of internet addiction, antidepressants, antipsychotics, opioid receptor antagonists, glutamate receptor antagonists, and psychostimulants and some antiepileptic, and especially valproate, are considered as potential drugs for the treatment of internet addiction [12].

This present study aimed to investigate the internet use in health care individuals and its impact on depression, self-esteem and social attachment on cognitive function of health care individuals and identify if internet addiction may cause depression, decrease in selfesteem, and changes in social attachment and cognitive decline in health care individuals. 


\section{MATERIALS AND METHODS}

This was a cross-sectional survey which included 110 healthcare individuals (Physician, Pharmacist, Psychologist, Social worker and Nurses) after providing their consent. This study conducted in Radianz healthcare and research private limited. Young's internet addiction test and depression score, self-esteem (Rosenberg's) score and MoCA were used to measure internet addiction and psychological variables. This study was two phased, baseline and follow up.

The individuals were explained with the prepared questionnaire for depression, self-esteem and cognitive function to correlate internet addiction (MoCA) by using depression score and self-esteem (Rosenberg's) Score. We included the individuals working in health care with relevant education and individual serving in health care (more than $3 \mathrm{y}$ ) without relevant education. The individuals not interested in enrolling for the study, mentally challenged and nonhealth care individuals were excluded.

\section{Statistical analysis}

Statistical analysis was done by using epidemiological information package (EPI 2012) developed by centre for disease control, Atlanta. Using this software range, frequencies, percentages, means, standard deviations, chi square, ' $t$ ' value and ' $p$ ' values were calculated. ' $\mathrm{t}$ ' test was used to test the significance of difference between quantitative variables and Yate's and Fisher's chi square tests for qualitative variables. A 'p' value less than 0.05 was taken to denote significant relationship.

\section{RESULTS}

Total 110 number of health care professional were involved in this study

Table 1: Internet addiction (IA)

\begin{tabular}{|c|c|c|c|c|c|c|c|}
\hline \multirow[t]{3}{*}{ Group } & \multicolumn{7}{|c|}{ Internet addiction } \\
\hline & \multicolumn{3}{|c|}{ Score } & \multicolumn{2}{|c|}{ Normal } & \multicolumn{2}{|c|}{ Abnormal } \\
\hline & Range & Mean & SD & No. & $\%$ & No. & $\%$. \\
\hline Physicians & $0-8$ & 4.32 & 1.91 & 13 & 59.1 & 9 & 40.9 \\
\hline Pharmacists & $0-8$ & 4.77 & 1.85 & 7 & 31.8 & 15 & 68.2 \\
\hline Psychologists & $1-8$ & 4.5 & 2.04 & 12 & 54.5 & 10 & 45.5 \\
\hline Social workers & $0-8$ & 5.18 & 2.3 & 6 & 27.3 & 16 & 72.7 \\
\hline Nurses & $0-8$ & 5.0 & 2.12 & 7 & 31.8 & 15 & 68.2 \\
\hline Total cases & $0-8$ & 4.75 & 2.04 & 45 & 40.9 & 65 & 59.1 \\
\hline '*p’ & 0.6267 & & & & & & \\
\hline
\end{tabular}

SD: Standard deviation, MoCA: Montreal cognitive assessment, IA: Internet addiction

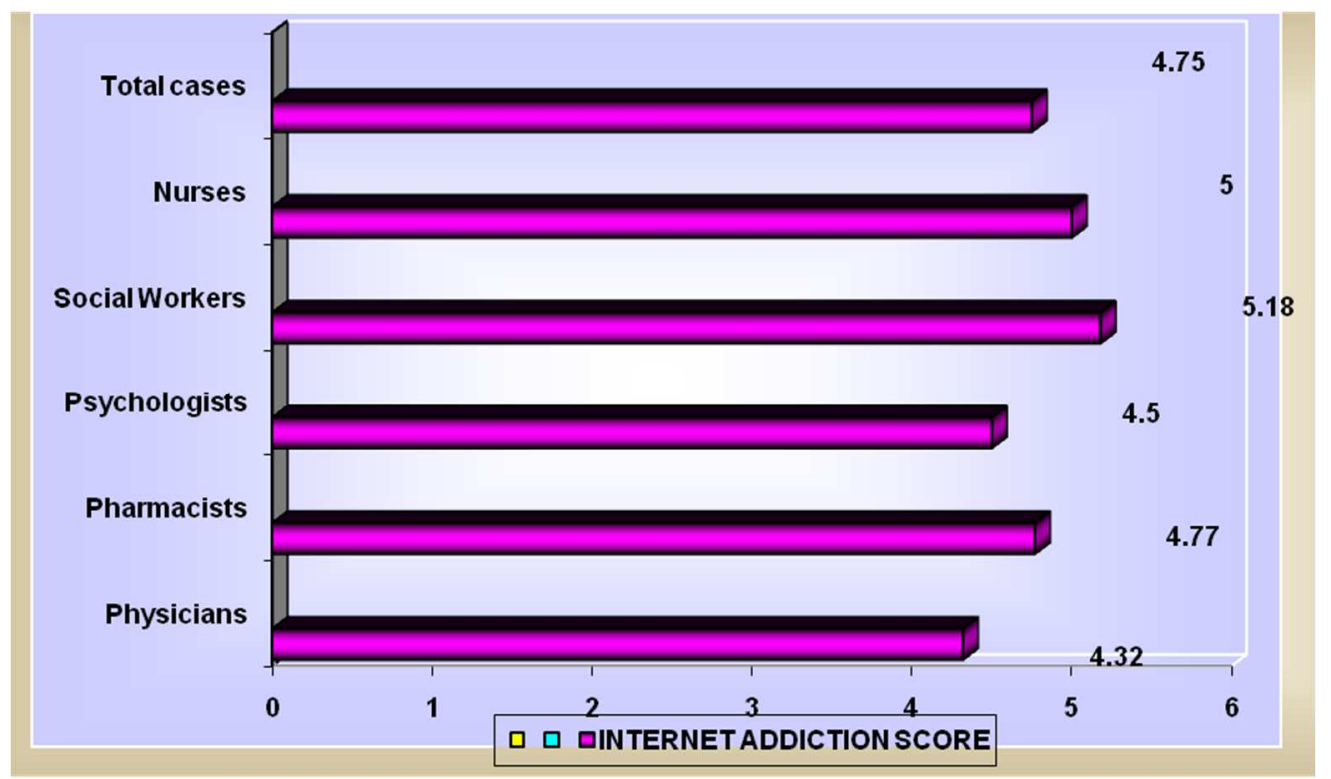

Fig. 1: Showed that social workers were more addicted $72.7 \%$ (Mean=5.18) followed by pharmacist and nurses $68.2 \%($ mean $=4.77)$ and physicians were least addicted $40.9 \%($ Mean $=4.32)$ but overall result was not significant $(P=0.6267)$

Table 2: Depression

\begin{tabular}{|c|c|c|c|c|c|c|c|}
\hline \multirow[t]{3}{*}{ Group } & \multicolumn{7}{|c|}{ Depression } \\
\hline & \multicolumn{3}{|c|}{ MDI score } & \multicolumn{2}{|c|}{ Normal } & \multicolumn{2}{|c|}{ Depressed } \\
\hline & Range & Mean & SD & No. & $\%$ & No. & $\%$ \\
\hline Physicians & $4-30$ & 16.0 & 8.5 & 13 & 59.1 & 9 & 40.9 \\
\hline Pharmacists & $7-29$ & 19.8 & 7.1 & 7 & 31.8 & 15 & 68.2 \\
\hline Psychologists & $5-30$ & 16.7 & 8.8 & 12 & 54.5 & 10 & 45.5 \\
\hline Social workers & $4-30$ & 19.5 & 8.5 & 8 & 36.4 & 14 & 63.6 \\
\hline Nurses & $4-30$ & 19.3 & 9.4 & 7 & 31.8 & 15 & 68.2 \\
\hline Total cases & $4-30$ & 18.3 & 8.5 & 47 & 42.7 & 63 & 57.3 \\
\hline ‘*p’ & 0.4507 & & & & & & \\
\hline
\end{tabular}




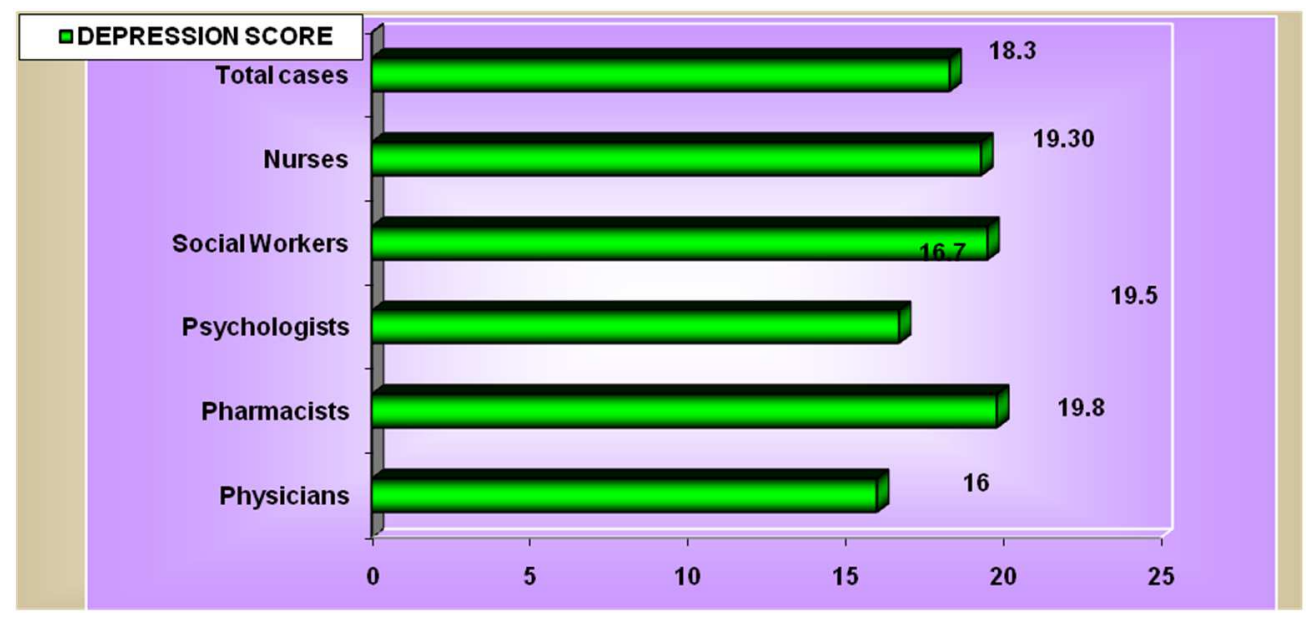

Fig. 2: Depicts that Pharmacist 68.2\% (mean=19.8) were more depressed because of internet addiction followed by Social worker $63.6 \%$ (mean=19.5) and Physician 40.9\% (mean=16) were least affected which was measured by the MDI score but overall result showed nonsignificant $(\mathrm{P}=\mathbf{0 . 4 5 0 7})$

Table 3: Self esteem

\begin{tabular}{|c|c|c|c|c|c|c|c|}
\hline \multirow[t]{3}{*}{ Group } & \multicolumn{7}{|c|}{ Self esteem } \\
\hline & \multicolumn{3}{|c|}{ Rosenberg's self-esteem score } & \multicolumn{2}{|c|}{ Normal } & \multicolumn{2}{|c|}{ Low self esteem } \\
\hline & Range & Mean & SD & No. & $\%$ & No. & $\%$ \\
\hline Physicians & $16-30$ & 22.7 & 3.8 & 22 & 100 & - & - \\
\hline Pharmacists & $12-28$ & 19.8 & 4.2 & 19 & 86.4 & 3 & 13.6 \\
\hline Psychologists & $11-27$ & 19.6 & 3.9 & 19 & 86.4 & 3 & 13.6 \\
\hline Social workers & $13-29$ & 18.9 & 4.2 & 16 & 72.7 & 6 & 27.3 \\
\hline Nurses & $12-25$ & 18.0 & 3.7 & 16 & 72.7 & 6 & 27.3 \\
\hline Total cases & $11-30$ & 19.8 & 4.2 & 92 & 83.6 & 18 & 16.4 \\
\hline${ }^{*}{ }^{*} \mathrm{p}$ & 0.0025 & & & & & & \\
\hline
\end{tabular}

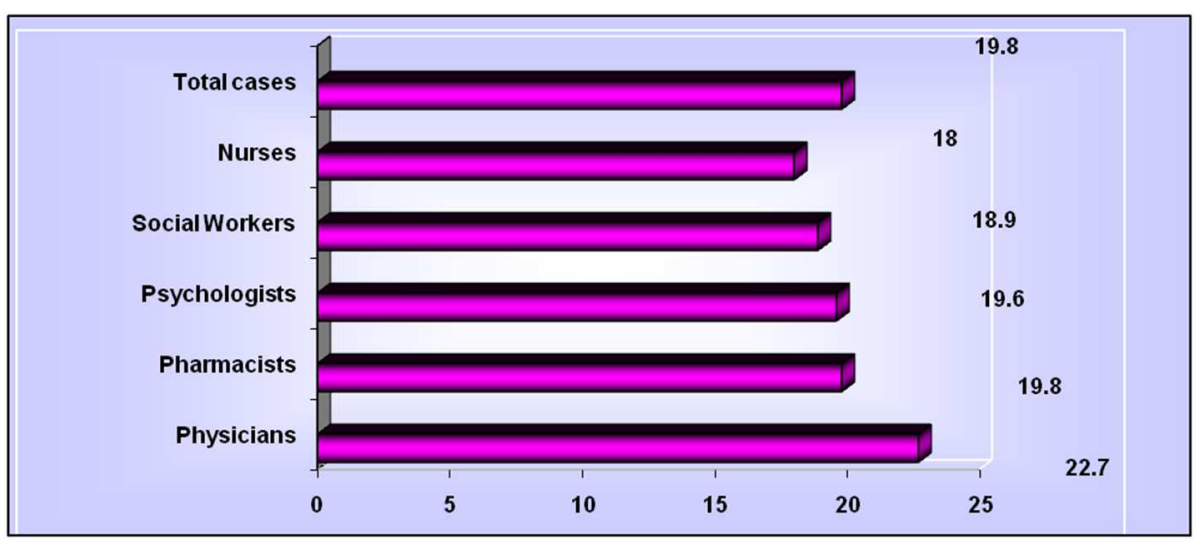

Fig. 3: Exhibits that Social worker and nurses $27.3 \%$ had low self-esteem due to internet addiction followed by Pharmacist and Psychologist 13.6\% andthe entire Physician were not affected which was measured by the Rosenberg's self-esteem score and the overall result were significant $(\mathrm{P}=\mathbf{0 . 0 0 2 5})$

Table 4: Montreal cognitive assessment

\begin{tabular}{|c|c|c|c|c|c|c|c|}
\hline \multirow[t]{3}{*}{ Group } & \multicolumn{7}{|c|}{ Montreal cognitive assessment (MoCA) } \\
\hline & \multicolumn{3}{|c|}{ MOCA score } & \multicolumn{2}{|c|}{ Normal } & \multicolumn{2}{|c|}{ Abnormal } \\
\hline & Range & Mean & SD & No. & $\%$ & No. & $\%$. \\
\hline Physicians & $23-28$ & 25.9 & 1.4 & 14 & 63.6 & 8 & 36.4 \\
\hline Pharmacists & $23-29$ & 26.2 & 1.9 & 11 & 50 & 11 & 50 \\
\hline Psychologists & $22-30$ & 26.3 & 2.2 & 15 & 68.2 & 7 & 31.8 \\
\hline Social workers & $21-30$ & 25.0 & 2.6 & 9 & 40.9 & 13 & 59.1 \\
\hline Nurses & $21-29$ & 25.4 & 2.2 & 8 & 36.4 & 14 & 63.6 \\
\hline Total cases & $21-30$ & 25.7 & 2.1 & 57 & 51.8 & 53 & 48.2 \\
\hline '*p' & 0.2189 & & & & & & \\
\hline
\end{tabular}




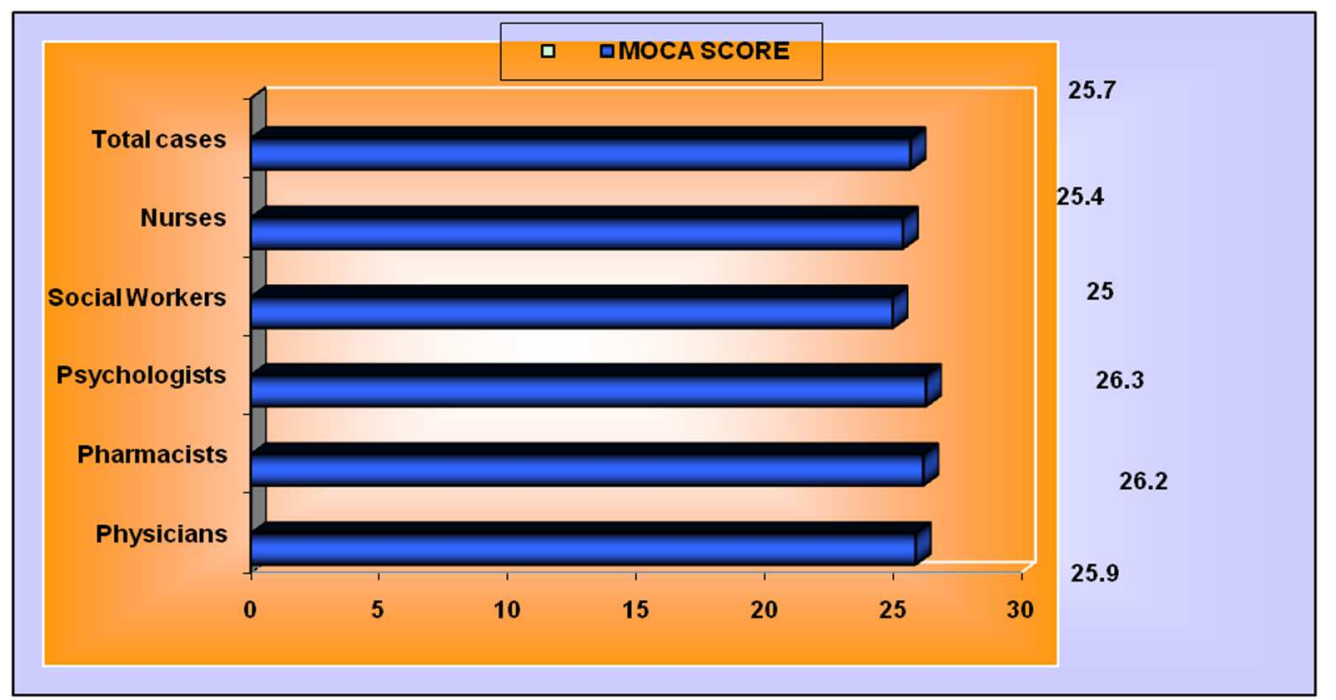

Fig. 4: Reveals that majority of cognitive functions of the Nurses $63.6 \%$ were affected followed by Social worker $59.1 \%$ and the cognitive function was least affected for the Physician (34.1\%) and psychologist (31.8\%) due to internet addiction

Table 5: Association between internet addiction and other variables

\begin{tabular}{lllll}
\hline Variable & Parameter & \multicolumn{2}{l}{ Value for internet addiction } & \multirow{2}{*}{ Addicted } \\
\cline { 3 - 5 } & & Normal & $2(4.3 \%)$ & $<0.0001$ \\
Depression & Normal (47) & $45(95.7 \%)$ & $63(100 \%)$ & 0.0005 \\
& Depressed (63) & $0(0) \%)$ & $48(52.2 \%)$ & $<0.0001$ \\
Self esteem & Normal (92) & $44(47.8 \%)$ & $17(94.4 \%)$ & \\
& Lowself-esteem(18) & $1(5.6 \%)$ & $14(24.6 \%)$ & \\
\hline \multirow{2}{*}{ MOCA score } & Normal (57) & $43(75.4 \%)$ & $96.2 \%)$ & \\
& Abnormal (53) & $2(3.8 \%)$ & & \\
\hline
\end{tabular}

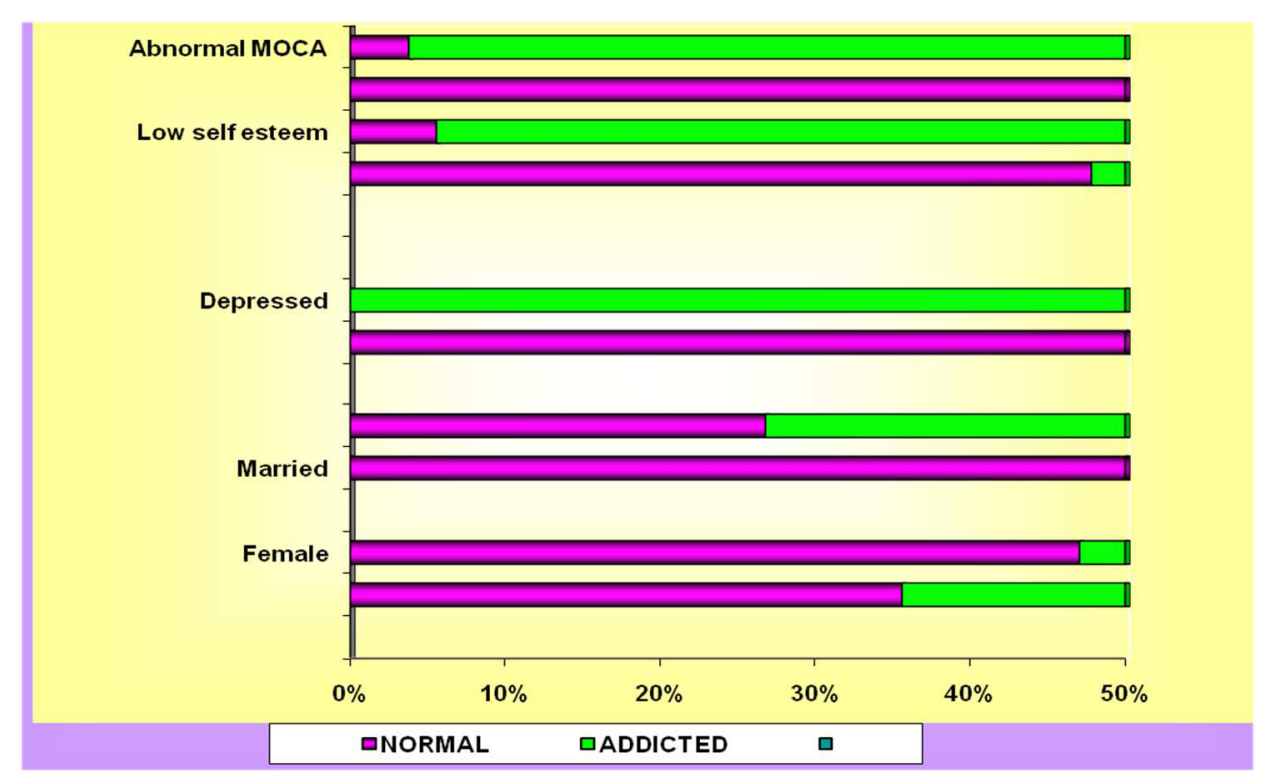

Fig. 5: Exhibits that females were less addicted as compared to male and unmarried were more addicted as compared to married. Majority of depressed, abnormal MoCA and low self-esteem individuals were more addicted to the internet as compared to normal individuals

Table 6: Relationship between baseline values and follow up values in internet addiction assessment

\begin{tabular}{llllll}
\hline Variable & Baseline & Follow up & \\
\cline { 2 - 5 } & Mean & SD & Mean & SD & *P \\
\hline Internet addiction score & 4.75 & 2.04 & 4.84 & 1.97 & 0.07636 \\
Depression score & 18.27 & 8.49 & 17.52 & 8.13 & 0.5016 \\
Self-esteem (Rosenberg's) score & 19.78 & 4.21 & 18.7 & 4.2 & 0.0578 \\
MOCA score & 25.75 & 2.14 & 25.23 & 2.14 & 0.0742 \\
\hline
\end{tabular}




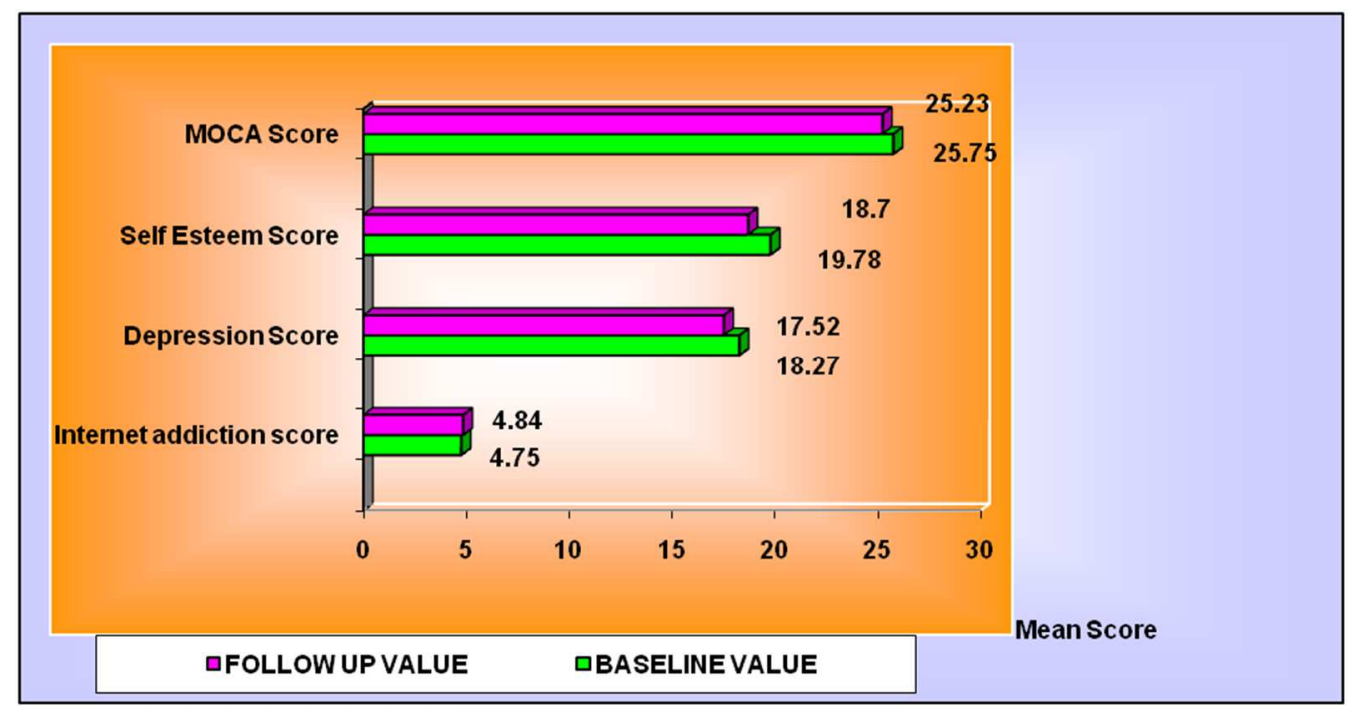

Fig. 6: Showed that internet addiction was slightly increased in follow up phase but statisticallynot significant $(\mathrm{P}=0.07636)$. MoCA $(P=0.0742)$, Self-steam $(P=0.0578)$, and depression score $(P=0.5016)$ were decreased in follow up but statistically not significant

\section{DISCUSSION}

The study was critical as it was selected only to health care individuals and the current study was first to internet addiction in healthcare individuals and various factors such asdepression, cognitive function and self-esteem associated with internet addiction.

In this current study, the addicted group's depression scores were significantly higher than those of the non-addicted group [2] but contradicted by Baris Afsar who found that depressive behavior was associated with lower use of internet and social media. Though this study, it is also clear that majority of depressed, cognitive declinedand low self-esteem individuals were more addicted to the internet as compared to normal individuals which was found to be significant. The negative mood states can drive people to use online interactions for mood regulation, a behavior that is associated with a deficiency in self-control; individuals with low self-control are more likely to use the internet inappropriately or to become addicted [5]. Depression and internet addiction have been found to be associated by several [13-15]. However, our study revealed that depressed individuals were more addicted to the internet and found to be significant by using depression score. Loneliness, low self-esteem, and lack of motivation may drive a depressed individual to net addiction. It also may serve as an easy means of getting social approval and thus bolstering an otherwise low self-esteem in such subjects [16]. In this study, the internet addiction was slightly raised in follow up phase which was statistically not significant $(\mathrm{P}=0.07636)$. MoCA, Self-steam, and depression score were decreased in follow up phase but statistically not significant.

\section{LIMITATION}

The current study has some limitations. The use of self-rating measurement to detect internet addiction can be considered as a limitation of the study. Because the study was cross-sectional, we could not establish a causal relationship and the current study was only conducted in some specific number of healthcare professionals and replicated in another setting or with participants from different age groups and backgrounds to reach more generalizable findings.

\section{CONCLUSION}

This study concluded that there is relationship between the internet addiction and depression, cognitive function and self-steam. The depressed individuals were more addicted to the internet followed by abnormal cognitive function and low self-esteem individuals. This study suggested that there is need to reduce the internet addiction among health care professionals then only can be thought about the common people.
Internet addiction may be a relevant clinical construct and early diagnostic tools thatneeds extensive research even in developing nations to explore the relationship. Depression is greatly associated with the internet addiction so if can we reduce the depression then can be reduced internet addiction.

\section{AUTHORS CONTRIBUTION}

Dr. Vikhram and Raja Soundara Pandian-Principal Investigator who conducted the study.

Dr. Rajesh Venkataraman-Contributed to research concept development, topic selection, questionnaire development and guided the research process and manuscript preparation.

Gopal Teli-Helped in literature review and manuscript writing.

Niraj Shrestha-Helped in statistical analysis.

\section{ACKNOWLEDGEMENT}

We would like to thank Radianz Healthcare and research private limited, Madurai to have supported the study.

\section{CONFLICTS OF INTERESTS}

The authors have no personal, professional, or ethical conflicts of interest in the publication of this study

\section{REFRENCES}

1. Orsala 0, Orsalb 0, Unsalc A, Ozalp S. Evaluation of internet addiction and depression among university students. Procedia Soc Behavioral Sci 2013;82:445-54.

2. Senormanc O, Senormanc G, Guclu O, Konkan R. Attachment and family functioning in patients with internet addiction. Gen Hosp Psychiatry 2014;36:203-7.

3. Shapira NA, Lessig MC, Goldsmith TD, Szabo ST, Lazoritz M, Gold MS, et al. Problematic internet use: proposed classification and diagnostic criteria. Depress Anxiety 2003;17:207-16.

4. Holden C. Behavioural addictions: do they exist? Science 2001;294:980-2.

5. Muller KW, Beutel ME, Wolfling K. A contribution to the clinical characterization of Internet addiction in a sample of treatment seekers: Validity of assessment, severity of psychopathology and type of co-morbidity. Compr Psychiatry 2014;55:770-7.

6. Kim K, Ryu E, Chon MY, Yeun EJ, Choi SY, Seo JS, et al. Internet addiction in Korean adolescents and its relation to depression and suicidal ideation: a questionnaire survey. Int J Nurs Stud 2006;43:185-92. 
7. Yang C, Choe B, Baity M, Lee J, Cho J. SCL-90-R and 16PF profiles of senior high school students with excessive internet use. Can J Psychiatry 2005;50:407-14.

8. Ko CH, Yen JY, Chen CS, Yeh YC, Yen CF. Predictive values of psychiatric symptoms for internet addiction in adolescents: a 2-year prospective study. Arch Pediatr Adolesc Med 2009;163:937-43.

9. Lin $\mathrm{CH}, \mathrm{Yu} \mathrm{SF}$. Adolescent Internet usage in Taiwan: exploring gender differences. J Adolesc 2008;43:317-31.

10. Ko CH, Liu TL, Wang PW, Chen CS, Yen CF, Yen JY. The exacerbation of depression, hostility, and social anxiety in the courseof internet addiction among adolescents: a prospective study. Compr Psychiatry 2014;55:1377-84.

11. Park MH, Park EJ, Choi J, Chai S, Lee JH, Lee C, et al. Preliminary study of Internet addiction and cognitive function in adolescents based on IQ tests. Psychiatry Res 2011;190:27581.

12. Przepiorka AM, Blachnio A, Miziak B, Czuczwar SJ. Clinical approaches to treatment of Internet addiction. Pharmacol Rep 2014;66:187-91.
13. Carli V, Durkee T, Wasserman D, Hadlaczky G, Despalins R, Kramarz E, et al. The association between pathological internet use and comorbid psychopathology: a systematic review. Psychopathology 2013;46:1-13.

14. Yen JY, Ko CH, Yen CF, Wu HY, Yang MJ. The comorbid psychiatric symptoms of Internet addiction: attention deficit and hyperactivity disorder (ADHD), depression, social phobia, and hostility. J Adolesc Health Care 2007;41:93-8.

15. Weinstein $A$, Lejoyeux $M$. Internet addiction or excessive internet use. Am J Drug Alcohol Abuse 2010;36:277-83.

16. Wartberg L, Sack PM, Petersen KU, Thomasius R. Psychopathology and achievement motivation in adolescents with pathological internet use. Prax Kinderpsychol Kinderpsychiatr 2011;60:719-34.

\section{How to cite this article}

- $\quad$ Rajesh Venkataraman, Vikhram, Raja Soundara Pandian, Gopal Teli, Niraj Shrestha. The relation between internet, depression, self-esteem and social attachment on cognitive function of health care individuals. Int J Pharm Pharm Sci 2017;9(7):144-149. 